\title{
Wheels within wheels: new transcriptional feedback loops in the Arabidopsis circadian clock
}

\author{
C. Robertson McClung
}

Address: Department of Biological Sciences, Dartmouth College, Class of 1978 Life Sciences Center, 78 College Street, Hanover, NH 03755-3563, USA

Email: c.robertson.mcclung@dartmouth.edu

Fl000Prime Reports 2014, 6:2 (doi:10.12703/P6-2)

This is an open-access article distributed under the terms of the Creative Commons Attribution-Non Commercial License (http://creativecommons.org/licenses/by-nc/3.0/legalcode), which permits unrestricted use, distribution, and reproduction in any medium, provided the original work is properly cited. You may not use this work for commercial purposes.

The electronic version of this article is the complete one and can be found at: http://fl000.com/prime/reports/b/6/2

\begin{abstract}
The circadian clock allows organisms to temporally coordinate their biology with the diurnal oscillation of the environment, which enhances plant performance. Accordingly, a fuller understanding of the circadian clock mechanism may contribute to efforts to optimize plant performance. One recurring theme in clock mechanism is coupled transcription-translation feedback loops. To date, the majority of plant transcription factors constituting these loops, including the central oscillator components CIRCADIAN CLOCK ASSOCIATED I (CCAI), LATE ELONGATED HYPOCOTYL (LHY), and TIMING OF CAB2 EXPRESSION I (TOCI), and the related PSEUDORESPONSE REGULATORS (PRRs), are transcriptional repressors, leading to a model of the clock emphasizing repressive interactions. Recent work, however, has revealed that a subset of the REVEILLE (RVE) family of Myb transcription factors closely related to CCAI and LHY are transcriptional activators in novel feedback transcription-translation feedback loops. Other recently identified transcriptional activators that contribute to clock function include LIGHT-REGULATED WD I (LWDI) and LWD2 and night light-inducible and clock-regulated transcription factors NIGHT LIGHT-INDUCIBLE AND CLOCK-REGULATEDI (LNKI) and LNK2. Collectively, these advances permit a substantial reconfiguration of the clock model.
\end{abstract}

\section{Introduction}

The alternation of day and night, a consequence of the rotation of the earth on its axis, means that organisms experience dramatic yet rhythmic and hence predictable environmental change. The circadian clock is an endogenous timekeeping mechanism that enables organisms not simply to respond as they experience environmental change but, importantly, to anticipate and prepare for coming change. This ability to coordinate with the environment enhances fitness in bacteria, plants, and animals [1]. Any fitness advantage accruing from circadian clock function has multiple potential bases because the circadian clock regulates many aspects of biology, including, in plants, basic metabolism, hormone signaling, and responses to biotic and abiotic stresses [2-4].
The molecular mechanisms of the circadian clock in eukaryotes studied to date, including fungi, flies, mammals, and plants, are rooted in coupled transcription-translation feedback loops (TTFLs) [5,6]. Initially these were thought to be relatively simple loops, but it has become clear that most eukaryotic circadian oscillators are based on multiple interlocked TTFLs [6]. Although eukaryotic clocks share this common architecture of multiple interlocked TTFLs, the transcription factors constituting TTFLs are largely distinct among plants and animals and fungi. Thus, efforts to manipulate the circadian clock in order to improve plant performance will require enhanced understanding of the oscillatory mechanism in plants. Excitingly, the last several years have witnessed tremendous advances in our understanding of the mechanism of the plant circadian 
clock. This report will describe some recent advances that pertain directly to the roles of transcriptional regulation in the oscillator mechanism.

\section{Evolution in the model of the plant circadian clock}

The initial model of the plant circadian clock was a negative feedback loop in which the PRR gene, TOC1, was posited to encode a positive regulator of two genes encoding $\mathrm{MYB}$ transcription factors, CCA1 and $L H Y$, which themselves encode repressors of TOC1 expression [7].

Over the next several years, a number of new interlocking loops were characterized and integrated into the clock model, primarily through analysis of mutants and of gene expression data. CCA1 HIKING EXPEDITION (CHE) is a TCP transcription factor that binds specifically to the CCA1 promoter as a transcriptional repressor [8]. CHE was identified through a yeast-one-hybrid screen of a library of Arabidopsis transcription factors. A variety of in vitro and in vivo studies confirmed that $\mathrm{CHE}$ binds to the CCA1 promoter as a repressor. This relationship is reciprocal, as CCA1 binds to the CHE promoter to repress transcription [8]. This study also established via chromatin immunoprecipitation (ChIP) studies that TOC1 binds to the CCA1 promoter [8].

Experimental and modeling studies supported a morning loop in which CCA1/LHY positively regulates $P R R 7$ and PRR9, which encode repressors of CCA1 and $L H Y[9,10]$. Modeling also predicted an evening loop in which a hypothetical component, Y, possibly including GIGANTEA (GI), activated TOC1, which repressed Y $[9,11]$.

Biochemical analyses have dramatically enriched our understanding of the evening loop. A set of three evening-peaking clock components, including EARLY FLOWERING 3 (ELF3), ELF4, and LUX ARRHYTHMO (LUX, also called PHYTOCLOCK 1 (PCL1) [12-16], were shown to assemble into a so-called "evening complex" (EC) $[17,18]$. LUX is a DNA-binding protein and recruits the EC, which functions as a transcriptional repressor, to targets that include PRR9 and LUX itself [16-20]. This negative autoregulation of the EC allowed a refinement of the model of the Arabidopsis clock, replacing hypothetical component $\mathrm{Y}$ with the EC [21].

A second set of studies revisited the long-standing interpretation of TOC1 as an activator of CCA1 and $L H Y$ expression, initially proposed because in a loss-offunction toc1 mutant background mRNA accumulation of CCA1 and $L H Y$ was diminished $[7,22]$. However, later studies showed that TOC1 overexpression reduced expression of CCA1 and LHY [23]. Moreover, the three
TOC1-related PRRs, PRR9, PRR7, and PRR5, were established as transcriptional repressors whose overlapping expression patterns served to provide sequential and extended repression of TOC 1 transcription throughout the day [24]. Thus, the role of TOC1 as a transcriptional activator was called into question.

Recent studies have established unambiguously that TOC1, like its PRR relatives, is a transcriptional repressor $[25,26]$. Genome-wide chromatin immunoprecipitation sequencing (ChIP-seq) identified TOC1 targets, which included morning-phased (CCA1, LHY, PRR9, and PRR7) and evening-phased (GI, ELF4, and LUX) clock genes. TOC1 binding peaked antiphase to target gene expression, and experimental manipulation of (either elevated or reduced) TOC1 expression affected target gene expression consistent with repression by TOC1 [26]. A second study showed that TOC1 bound the CCA1 promoter in vitro and in vivo. Chemical induction of TOC1 repressed CCA1 and LHY expression [25]. Transient overexpression of TOC1 allowed the identification of both upregulated and downregulated genes [25], leaving open the possibility that TOC1 may also function, directly or indirectly, as a transcriptional activator. Although both TOC1 and its three PRR relatives share repressor function, there are intriguing differences among them; the repressor function of PRR9, PRR7, and PRR5 requires a co-repressor, encoded by members of the TOPLESS/TOPLESS-RELATED (TPL/TPR) gene family [27], whereas the repressor function of TOC1 seems to be intrinsic [25]. Another recent demonstration of co-repressor function in the clock mechanism is that CCA1 and LHY recruit the COP10-DET1-DDB1 (CDD) complex to the TOC1 and GI promoters and that DET1 (DE-ETIOLATED1) serves as a transcriptional co-repressor necessary for CCA1- and LHY-mediated inhibition of TOC1 and GI transcription [28].

The characterization of TOC1, PRR9/PRR7/PRR5, and the EC as transcriptional repressors was integrated into a new model of the clock as a three-component repressilator, a ring oscillator consisting of three repressors, CCA1/LHY, the EC, and PRR9/PRR7/PRR5/TOC1 [21]. Although this model is quite attractive and does a very good job in matching a variety of experimental data, it is clearly an oversimplification. For example, TOC1, PRR9, PRR7, and PRR5 are pooled into a single repressor, and CCA1 and LHY are pooled as a second repressor. However, these components are not simply redundant. For example, CCA1 and LHY can be distinguished by their temperature response, with LHY more important than CCA1 for clock function at higher temperatures and CCA1 more important than LHY at lower temperatures [29]. Similarly, among EC components, ELF3 and ELF4 
show dampened transcript cycling in the cold, whereas LUX cycling maintains a robust cycling amplitude [30]. TOC1 and the PRRs are all transcriptional repressors, but they exhibit temporally distinct expression patterns, and mutants defective in PRR function display different phenotypes-most obviously toc1 mutants have a short period [31] whereas prr7 and prr9 mutants have a long period and the double prr7 prr9 mutant has an extremely long period at high temperatures but has a wildtype period at low temperatures [32-34]. A second oversimplification is that the model fails to incorporate posttranscriptional control, which is becoming increasingly prominent in the plant clock. Among the PRRs, PRR5 has been shown to interact with TOC1 and this interaction regulates TOC1 phosphorylation and nucleocytoplasmic partitioning [35]. Considerable recent work emphasizes a role for alternative splicing in plant clock function [36-42]. Phase-dependent phosphorylation of CCA1 alters its DNA-binding affinity [43]. TOC1 and all the PRRs undergo clock-dependent changes in the phosphorylation state [44]. TOC1 and PRR5 show clock-regulated proteasomal degradation mediated by interaction with the F-Box protein ZEITLUPE (ZTL) [44-46].

A second prominent feature of the repressilator model is, as noted by David Somers, "a dearth of activators" [47]. Of course, a repressor of a repressor is formally an activator. In this sense, CCA1 and LHY could be activators of PRR7 and PRR9 by virtue of repression of the EC, itself a repressor of PRR7 and PRR9. Nonetheless, it seems unlikely that the plant clock TTFL would function without transcriptional activators. Indeed, several recent studies have defined roles for several transcriptional activators in the plant oscillator mechanism. Although CCA1 is a repressor, it can also function as a transcriptional activator when transiently expressed in protoplasts [41]. Indeed, in the cca1-11 lhy-21 double-mutant background, cold induction of the three C-REPEAT BINDING FACTOR $(C B F)$ genes is diminished, implicating CCA1 and LHY as transcriptional activators of these targets.

A second example of activation of gene expression is by LIGHT-REGULATED WD1 (LWD1) and LWD2. The lwd1 $l w d 2$ double mutant has a significantly shortened period, and the expression of multiple clock genes is greatly reduced [48,49]. ChIP experiments established that LWD1 binds directly to the PRR9, PRR5, and TOC1 promoters, implicating it as a transcriptional activator of these genes [49]. $L W D 1$ and $L W D 2$ expression is greatly attenuated in a prr9 mutant, suggesting that PRR9 may be an activator of their expression. However, direct interaction of PRR9 with the LWD1 and LWD2 promoters has not been demonstrated and, given the determination that the PRRs are repressors [24], it may be that this positive regulation of $L W D 1$ and $L W D 2$ by PRR9 is indirect, via the repression of a repressor.

CCA1 and $L H Y$ are members of a larger clade of Myb transcription factor genes, including eight REVEILLE (RVE) genes, and most of these RVEs show circadianregulated expression [50,51]. Three of these, RVE1, RVE2 (also called CIRCADIAN 1/CIR1), and RVE7 (also called EARLY-PHYTOCHROME-RESPONSIVE1/EPR1), chiefly play roles in clock output pathways [52-54]. However, RVE8 (also called LHY-CCA1-LIKE5/LCL5) seems to function more centrally in the clock oscillator. RVE8 binds to the TOC1 promoter, where it is associated with increased acetylation of histone $\mathrm{H} 3$, which is associated with increased transcription [55]. RVE8 also binds to the evening element (EE) in the PRR5 promoter to activate PRR5 transcription [51,56]. The four remaining RVEs (RVE3, 4, 5, and 6) also bind to the EE [51,57], raising the possibility of functional redundancy among them. Indeed, mutants defective in RVE4 or RVE6 function have little effect on period length but, when combined in either double- or triple-mutant combinations, enhance the longperiod phenotype of rve8-1 [56]. Earlier work had identified an EE-binding activity present in wildtype plant extracts in the afternoon, which had been suggested as a potential activator of evening-phased clock genes, such as PRR5 and TOC1 [58]. This recent work strongly suggests that RVE4, RVE6, and RVE8 constitute this afternoon-phased activator of PRR5 and TOC1 as well as of other evening-phased clock genes, including GI, ELF4, and LUX, and apparently of the morning-phased PRR9 [56]. Several pieces of evidence indicate that the PRRs feed back to repress RVE8. RVE8 expression increases in the prr 5 prr7 prr9 triple mutant [51], and PRR5 binds directly to the RVE8 promoter [59]. Thus, RVE8 (and presumably RVE4 and RVE6) and PRR5 (and possibly PRR7 and PRR9) constitute a negative feedback TTFL [56].

Very recently, two LNK transcription factors, LNK1 and LNK2, have been shown to activate transcription of afternoon-peaking clock-regulated genes, including the critical clock genes PRR5 and the EC component ELF4, as well as the clock regulated F-BOX protein gene FKF1 that plays a critical role in flowering time [60]. TOC1 and PRR9/7/5 each bind to the LNK1 and LNK2 promoters, and $L N K$ mRNAs accumulate to increased levels in toc1 and in prr7 prr9 mutants. Thus, the LNKs and the PRRs form negative feedback loops in which the LNKs activate PRR transcription, and the PRRs feed back to repress $L N K$ transcription.

\section{Future directions}

Although Somers's "dearth of activators" has been at least partially redressed by the identification of LWDs as 
transcriptional activators of PRR9, of RVE8 (and RVE4 and RVE6) as transcriptional activators of TOC1, PRR5, and other EE-regulated genes, and of LNKs as transcriptional activators of PRR5 and ELF4, a number of key questions remain. The regulation of CCA1 and $L H Y$ remains incompletely resolved. Are there transcriptional activators of these two critical clock genes? Moreover, although these two genes are typically pooled in our consideration and in our models, they can be distinguished on a number of grounds. As mentioned above, the expression of CCA1 and $L H Y$ differs in response to temperature, contributing to temperature compensation of the clock, but it remains unclear how this is effected. More broadly, chromatin modifications have only been mentioned in passing.

This report has focused on transcriptional regulation but included a partial enumeration of some of the levels of post-transcriptional regulation employed by the plant circadian clock. One emerging area is the role of nucleocytoplasmic partitioning in the regulation of clock protein function. As mentioned above, PRR5 regulates not only the phosphorylation of TOC1 but also the nuclear import and subnuclear localization of TOC1 [35], with an obvious implication for TOC1 as a transcriptional repressor. Two recent papers extend this mode of regulation, via subnuclear and nuclear-cytoplasmic partitioning, to a second clock component, GI [61,62].

The circadian clock is not unusual in employing regulatory mechanisms that include transcriptional and post-transcriptional aspects, but the implications for complexity and the challenges of assembling a complete and nuanced model of the clock mechanism are quite obviously significant. While the challenges are great, the rewards will be commensurate. Plant biologists face the daunting challenge of providing increased agricultural production in the face of a declining agricultural landmass that is being altered by resource depletion, pollution, and a changing climate. Impaired circadian function reduces plant growth and fitness, offering the hypothesis that optimizing circadian function will enhance crop productivity, particularly in crops grown over broad latitudinal ranges. Greater refinement of our understanding of the circadian clock mechanism is necessary to inform manipulation of the circadian clock towards the goal of enhancing agricultural productivity.

\section{Abbreviations}

CCA1, CIRCADIAN CLOCK ASSOCIATED 1; CHE, CCA1 HIKING EXPEDITION; ChiP, chromatin immunoprecipitation; EC, evening complex; EE, evening element; ELF, EARLY FLOWERING; GI, GIGANTEA;
LHY, LATE ELONGATED HYPOCOTYL; LNK, NIGHT LIGHT-INDUCIBLE AND CLOCK-REGULATED, LNK; LUX, LUX ARRHYTHMO; LWD, LIGHT-REGULATED WD; PRR, PSEUDO-RESPONSE REGULATOR; RVE, REVEILLE; TOC1, TIMING OF CAB2 EXPRESSION 1; TTFL, transcription-translation feedback loop.

\section{Disclosures}

The author declares that he has no disclosures.

\section{Acknowledgments}

This work was supported by grants from the National Science Foundation (IOS-0923752 and IOS-1025965) and from the Rural Development Administration, Republic of Korea (Next-Generation BioGreen 21 Programme, Systems and Synthetic Agrobiotech Centre, no. PJ009615).

\section{References}

I. Yerushalmi S, Green RM: Evidence for the adaptive significance of circadian rhythms. Ecol Lett 2009, I2:970-98I.

2. McClung CR: The genetics of plant clocks. Adv Genet 201 I, 74: $105-138$.

3. Haydon MJ, Hearn TJ, Bell LJ, Hannah MA, Webb AAR: Metabolic regulation of circadian clocks. Sem Cell Dev Biol 20I3, 24:4I4-42I.

4. Kinmonth-Schultz HA, Golembeski GS, Imaizumi T: Circadian clock-regulated physiological outputs: dynamic responses in nature. Sem Cell Dev Biol 20I3, 24:407-4I3.

5. Dunlap JC: Molecular bases for circadian clocks. Cell 1999, 96: 27I-290.

6. Zhang EE, Kay SA: Clocks not winding down: unravelling circadian networks. Nat Rev Mol Cell Biol 2010, I I:764-776.

7. Alabadí D, Oyama T, Yanovsky MJ, Harmon FG, Más P, Kay SA: Reciprocal regulation between TOCI and LHYICCAI within the Arabidopsis circadian clock. Science 200 I, 293:880-883.

FlOOOPrime RECOMMENDED

8. Pruneda-Paz JL, Breton G, Para A, Kay SA: A functional genomics approach reveals $\mathrm{CHE}$ as a novel component of the Arabidopsis circadian clock. Science 2009, 323:|48|-| 485.

FlOOOPrime RECOMMENDED

9. Locke JCW, Kozma-Bognár L, Gould PD, Fehér B, Kevei É, Nagy F, Turner MS, Hall A, Millar AJ: Experimental validation of a predicted feedback loop in the multi-oscillator clock of Arabidopsis thaliana. Mol Syst Biol 2006, 2:59.

\section{FlOOOPrime}

RECOMMENDED

10. Zeilinger MN, Farré EM, Taylor SR, Kay SA, Doyle FJ III: A novel computational model of the circadian clock in Arabidopsis that incorporates PRR7 and PRR9. Mol Syst Biol 2006, 2:58.

II. Locke JCW, Southern MM, Kozma-Bognar L, Hibberd V, Brown PE, Turner MS, Millar AJ: Extension of a genetic network model by iterative experimentation and mathematical analysis. Mol Syst Biol 2005, I:0013.

FlOOOPrime RECOMMENDED

12. Hicks KA, Millar AJ, Carré IA, Somers DE, Straume M, MeeksWagner DR, Kay SA: Conditional circadian dysfunction of the 
Arabidopsis early-flowering 3 mutant. Science 1996, 274: 790-792.

\section{FlOOOPrime}

13. Doyle MR, Davis SJ, Bastow RM, McWatters HG, Kozma-Bognar L, Nagy F, Millar AJ, Amasino RM: The ELF4 gene controls circadian rhythms and flowering time in Arabidopsis thaliana. Nature 2002, 419:74-77.

\section{FlOOOPrime}

\section{RECOMMENDED}

14. Hazen SP, Schultz TF, Pruneda-Paz JL, Borevitz JO, Ecker JR, Kay SA: LUX ARRHYTHMO encodes a Myb domain protein essential for circadian rhythms. Proc Natl Acad Sci USA 2005, I02: 10387-10392

\section{FlOOOPrime
RECOMMENDED}

15. Onai K, Ishiura M: PHYTOCLOCKI encoding a novel GARP protein essential for the Arabidopsis circadian clock. Genes Cells 2005, 10:963-972.

\section{FlOOOPrime
RECOMMENDED}

16. Kolmos E, Nowak M, Werner M, Fischer K, Schwarz G, Mathews S, Schoof H, Nagy F, Bujnicki JM, Davis SJ: Integrating ELF4 into the circadian system through combined structural and functional studies. HFSP J 2009, 3:350-366.

\section{FlOOOPrime} RECOMMENDED

17. Helfer A, Nusinow DA, Chow BY, Gehrke AR, Bulyk ML, Kay SA: LUX ARRHYTHMO encodes a nighttime repressor of circadian gene expression in the Arabidopsis core clock. Curr Biol 20II, 2I:|26-|33.

\section{FlOOOPrime \\ RECOMMENDED}

18. Nusinow DA, Helfer A, Hamilton EE, King JJ, Imaizumi T, Schultz TF, Farre EM, Kay SA: The ELF4-ELF3-LUX complex links the circadian clock to diurnal control of hypocotyl growth. Nature $2011,475: 398-402$.

\section{FlOOOPrime}

\section{RECOMMENDED}

19. Herrero E, Kolmos E, Bujdoso N, Yuan Y, Wang M, Berns MC, Uhlworm H, Coupland G, Saini R, Jaskolski M, Webb A, Gonçalves J, Davis S]: EARLY FLOWERING4 recruitment of EARLY FLOWERING3 in the nucleus sustains the Arabidopsis circadian clock. Plant Cell 2012, 24:428-443.

\section{FlOOOPrime
RECOMMENDED}

20. Chow BY, Helfer A, Nusinow DA, Kay SA: ELF3 recruitment to the PRR9 promoter requires other Evening Complex members in the Arabidopsis circadian clock. Plant Signal Behav 2012, 7:1-4.

\section{FlOOOPrime}

\section{RECOMMENDED}

21. Pokhilko A, Fernández AP, Edwards KD, Southern MM, Halliday KJ, Millar AJ: The clock gene circuit in Arabidopsis includes a repressilator with additional feedback loops. Mol Syst Biol 2012, 8:574.

22. Más P, Alabadí D, Yanovsky MJ, Oyama T, Kay SA: Dual role of TOCI in the control of circadian and photomorphogenic responses in Arabidopsis. Plant Cell 2003, I 5:223-236.

23. Makino S, Matsushika A, Kojima M, Yamashino T, Mizuno T: The APRRI/TOCI quintet implicated in circadian rhythms of Arabidopsis thaliana: I. Characterization with APRRIoverexpressing plants. Plant Cell Physiol 2002, 43:58-69.

24. Nakamichi $\mathrm{N}$, Kiba $\mathrm{T}$, Henriques $\mathrm{R}$, Mizuno $\mathrm{T}$, Chua $\mathrm{N}-\mathrm{H}$, Sakakibara H: PSEUDO-RESPONSE REGULATORS 9, 7 and 5 are transcriptional repressors in the Arabidopsis circadian clock. Plant Cell 2010, 22:594-605

\section{FlOOOPrime}

25. Gendron JM, Pruneda-Paz JL, Doherty CJ, Gross AM, Kang SE, Kay SA: Arabidopsis circadian clock protein, TOCI, is a DNAbinding transcription factor. Proc Natl Acad Sci USA 2012, I09: $3 \mid 67-3172$

\section{FlOOOPrime}

\section{RECOMMENDED}

26. Huang W, Pérez-García P, Pokhilko A, Millar AJ, Antoshechkin I, Riechmann JL, Mas P: Mapping the core of the Arabidopsis circadian clock defines the network structure of the oscillator. Science 20I2, 336:75-79.

\section{FIOOOPrime
RECOMMENDED}

27. Wang L, Kim J, Somers DE: Transcriptional corepressor TOPLESS complexes with pseudoresponse regulator proteins and histone deacetylases to regulate circadian transcription. Proc Natl Acad Sci USA 2013, I I 0:761-766.

\section{FlOOOPrime}

RECOMMENDED

28. Lau OS, Huang X, Charron J-B, Lee J-H, Li G, Deng XW: Interaction of Arabidopsis DETI with CCAI and LHY in mediating transcriptional repression in the plant circadian clock. Mol Cell 20II, 43:703-7I2.

\section{FlOOOPrime}

\section{RECOMMENDED}

29. Gould PD, Locke JCW, Larue C, Southern MM, Davis SJ, Hanano S, Moyle R, Milich R, Putterill J, Millar AJ, Hall A: The molecular basis of temperature compensation in the Arabidopsis circadian clock. Plant Cell 2006, I 8: I I77-I I87.

30. Bieniawska Z, Espinoza C, Schlereth A, Sulpice R, Hincha DK, Hannah MA: Disruption of the Arabidopsis circadian clock Is responsible for extensive variation in the cold-responsive transcriptome. Plant Physiol 2008, I47:263-279.

3I. Millar AJ, Carré IA, Strayer CA, Chua N-H, Kay SA: Circadian clock mutants in Arabidopsis identified by luciferase imaging. Science 1995, 267:1161-1163.

32. Farré EM, Harmer SL, Harmon F.G., Yanovsky MJ, Kay SA: Overlapping and distinct roles of PRR7 and PRR9 in the Arabidopsis circadian clock. Curr Biol 2005, I 5:47-54

\section{FlOOOPrime} RECOMMENDED

33. Salomé PA, McClung CR: PSEUDO-RESPONSE REGULATOR 7 and 9 are partially redundant genes essential for the temperature responsiveness of the Arabidopsis circadian clock. Plant Cell 2005, 17:791-803.

34. Salomé PA, Weigel D, McClung CR: The role of the Arabidopsis morning loop components CCAI, LHY, PRR7 and PRR9 in temperature compensation. Plant Cell 2010, 22:3650-366I.

35. Wang L, Fujiwara S, Somers DE: PRR5 regulates phosphorylation, nuclear import and subnuclear localization of TOCI in the Arabidopsis circadian clock. EMBO J 2010, 29:1903-1915.

\section{FIOOOPrime
RECOMMENDED}

36. Filichkin SA, Priest HD, Givan SA, Shen R, Bryant DW, Fox SE, Wong W-K, Mockler TC: Genome-wide mapping of alternative splicing in Arabidopsis thaliana. Genome Res 2010, 20:45-58.

\section{FlOOOPrime}

37. Sanchez SE, Petrillo E, Beckwith EJ, Zhang X, Rugnone ML, Hernando CE, Cuevas JC, Godoy Herz MA, Depetris-Chauvin A, Simpson CG, Brown JWS, Cerdán PD, Borevitz JO, Mas P, Ceriani MF, Kornblihtt AR, Yanovsky MJ: A methyl transferase 
links the circadian clock to the regulation of alternative splicing. Nature 2010, 468: I I2-II6.

\section{FlOOOPrime}

38. Deng X, Gu L, Liu C, Lu T, Lu F, Lu Z, Cui P, Pei Y, Wang B, Hu S, Cao $X$ : Arginine methylation mediated by the Arabidopsis homolog of PRMT5 is essential for proper pre-mRNA splicing. Proc Natl Acad Sci USA 2010, 107:19114-19119.

39. Hong S, Song H-R, Lutz K, Kerstetter RA, Michael TP, McClung CR: Type II Protein Arginine Methyltransferase PRMT5 is required for circadian period determination in Arabidopsis thaliana. Proc Natl Acad Sci USA 2010, 107:21211-21216.

40. James $A B$, Syed NH, Bordage S, Marshall J, Nimmo GA, Jenkins GI, Herzy P, Brown JWS, Nimmo HG: Alternative splicing mediates responses of the Arabidopsis circadian clock to temperature changes. Plant Cell 2012, 24:96I-98I.

4I. Seo PJ, Park M-J, Lim M-H, Kim S-G, Lee M, Baldwin IT, Park C-M: A selfregulatory circuit of CIRCADIAN CLOCK-ASSOCIATEDI underlies the circadian clock regulation of temperature responses in Arabidopsis. Plant Cell 2012, 24:2427-2442.

42. Wang X, Wu F, Xie Q, Wang H, Wang Y, Yue Y, Gahura O, Ma S, Liu L,

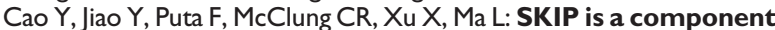
of the spliceosome linking alternative splicing and the circadian clock in Arabidopsis. Plant Cell 2012, 24:3278-3295.

43. Portolés $S$, Más $P$ : The functional interplay between protein kinase CK2 and CCAI transcriptional activity is essential for clock temperature compensation in Arabidopsis. PLoS Genet 2010, 6:el001201.

\section{FlOOOPrime} RECOMMENDED

44. Fujiwara S, Wang L, Han L, Suh SS, Salomé PA, McClung CR, Somers DE: Post-translational regulation of the circadian clock through selective proteolysis and phosphorylation of pseudoresponse regulator proteins. J Biol Chem 2008, 283:23073-23083.

\section{FlOOOPrime

RECOMMENDED

45. Más P, Kim W-Y, Somers DE, Kay SA: Targeted degradation of TOCI by ZTL modulates circadian function in Arabidopsis thaliana. Nature 2003, 426:567-570.

\section{FlOOOPrime}

\section{RECOMMENDED}

46. Kim W-Y, Geng R, Somers DE: Circadian phase-specific degradation of the F-box protein ZTL is mediated by the proteasome. Proc Natl Acad Sci USA 2003, 1 00:4933-4938.

47. Somers DE: The Arabidopsis clock: time for an about-face? Genome Biol 2012, I3:I53.

48. Wu J-F, Wang Y, Wu S-H: Two new clock proteins, LWDI and LWD2, regulate Arabidopsis photoperiodic flowering. Plant Physiol 2008, I48:948-959.

\section{FlOOOPrime}

\section{RECOMMENDED}

49. Wang $Y$, Wu J-F, Nakamichi N, Sakakibara H, Nam H-G, Wu S-H: LIGHT-REGULATED WDI and PSEUDO-RESPONSE REGULATOR9 form a positive feedback regulatory loop in the Arabidopsis circadian clock. Plant Cell 20I I, 23:486-498.

\section{FIOOOPRIM
RECOMMENDED}

50. Covington MF, Harmer SL: The circadian clock regulates auxin signaling and responses in Arabidopsis. PLoS Biol 2007, 5:e222.

\section{FlOOOPrime}

\section{RECOMMENDED}

5I. Rawat R, Takahashi N, Hsu PY, Jones MA, Schwartz J, Salemi MR, Phinney BS, Harmer SL: REVEILLE8 and PSEUDO-REPONSE
REGULATOR5 form a negative feedback loop within the Arabidopsis circadian clock. PLoS Genet 20I I, 7:I6.

\section{FlOOOPrime}

52. Kuno S, Møller SG, Shinomura T, Xu XM, Chua N-H, Furuya M: The novel MYB protein EARLY-PHYTOCHROME-RESPONSIVE I Is a component of a slave circadian oscillator in Arabidopsis. Plant Cell 2003, I5:2476-2488.

53. Zhang X, Chen Y, Wang Z-Y, Chen Z, Gu H, Qu L-J: Constitutive expression of CIRI (RVE2) affects several circadian-regulated processes and seed germination in Arabidopsis. Plant J 2007, 5 I : 512-525.

54. Rawat R, Schwartz J, Jones MA, Sairanen I, Cheng $Y$, Andersson CR, Zhao Y, Ljung K, Harmer SL: REVEILLE I, a Myb-like transcription factor, integrates the circadian clock and auxin pathways. Proc Natl Acad Sci USA 2009, 106:16883-16888.

55. Farinas B, Mas P: Functional implication of the MYB transcription factor RVE8/LCL5 in the circadian control of histone acetylation. Plant J 201 I, 66:318-329.

\section{FlOOOPrime
RECOMMENDED}

56. Hsu PY, Devisetty UK, Harmer SL: Accurate timekeeping is controlled by a cycling activator in Arabidopsis. elife Sciences $2013,2$.

\section{FIOOOPrime}

57. Gong $W$, He K, Covington MF, Dinesh-Kumar SP, Snyder M, Harmer SL, Zhu X, Deng XW: The development of protein microarrays and their applications in DNA-protein and protein-protein interaction analyses of Arabidopsis transcription factors. Mol Plant 2008, I:27-4I.

\section{FIOOOPRIM
RECOMMENDED}

58. Harmer SL, Kay SA: Positive and negative factors confer phasespecific circadian regulation of transcription in Arabidopsis. Plant Cell 2005, I 7:1926-1940.

\section{FlOOOPrime \\ RECOMMENDED}

59. Nakamichi N, Kiba T, Kamioka M, Suzuki T, Yamashino T, Higashiyama T, Sakakibara H, Mizuno T: Transcriptional repressor PRR5 directly regulates clock-output pathways. Proc Natl Acad SCi USA 2012, 109.

\section{FlOOOPrime}

\section{RECOMMENDED}

60. Rugnone ML, Faigón Soverna A, Sanchez SE, Schlaen RG Hernando CE, Seymour DK, Mancini E, Chernomoretz A, Weigel D, Más P, Yanovsky MJ: LNK genes integrate light and clock signaling networks at the core of the Arabidopsis oscillator. Proc Natl Acad Sci USA 2013, I I 0:12120-12125.

\section{FlOOOPrime}

6I. Kim Y, Han S, Yeom M, Kim H, Lim J, Cha J-Y, Kim W-Y, Somers DE, Putterill J, Nam HG, Hwang D: Balanced nucleocytosolic partitioning defines a spatial network to coordinate circadian physiology in plants. Dev Cell 2013, 26:73-85.

\section{FlOOOPrime} RECOMMENDED

62. Kim Y, Lim J, Yeom M, Kim H, Kim J, Wang L, Kim WY, Somers DE, Nam HG: ELF4 regulates GIGANTEA chromatin access through subnuclear sequestration. Cell Rep 2013 , 3:67I -677.

FlOOOPrime RECOMMENDED 